\title{
Endoscopic curative resection of undifferentiated early gastric cancer
}

High definition endoscopy has improved the diagnosis of early gastric cancer but still has a miss rate of $20 \%-25 \%$. Magnification endoscopy with narrow-band imaging (NBI) helps to further characterize histology in early gastric cancer [1 - 3]. A 62-year-old woman attended screening esophagogastroduodenoscopy, and white-light endoscopy showed a slightly depressed lesion of size $10 \times 5 \mathrm{~mm}$ (Paris type 0 -IIc) on the anterior wall of the stomach in the antrum. NBI showed a line of demarcation with absent microsurface pattern and irregular microvascular pattern [4]. Near focus showed a dilated and tortuous corkscrew type of microvascular pattern and intralobular

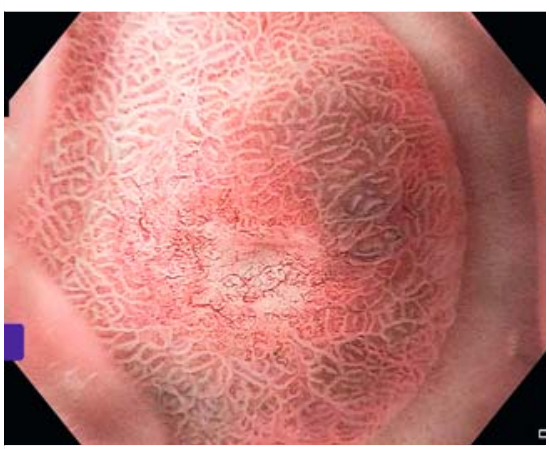

- Fig. 1 Magnification narrow-band imaging. Line of demarcation, irregular/ absent microsurface pattern, and corkscrew microvascular pattern. loop type 2 pattern ( $\mathbf{F i g . 1}$ ), as described by Nakayoshi et al., which was suggestive of poorly differentiated adenocarcinoma [1,5]. Biopsies showed a signet cell type of carcinoma.

Intramucosal undifferentiated type adenocarcinoma of size $\leq 2 \mathrm{~cm}$ is a candidate for endoscopic resection under expanded criteria in Japanese guidelines 2018. Circumferential marking was done using a noninsulation-tipped endoscopic submucosal dissection knife under Forced Coag mode ( Video 1 ). Submucosal in- jection using a 25-gauge needle with indigo carmine was performed to lift the lesion ( $>$ Fig.2a). An initial mucosal incision was performed on the proximal side of the lesion with the same knife and incision was completed using Endocut I ( $\triangleright$ Fig. 2 b). Bleeding was controlled using Coagrasper. Dissection was completed using the ITknife2 (Olympus Corp., Tokyo, Japan) ( Fig. 2c).

The resected specimen measured $40 \times$ $25 \times 2 \mathrm{~mm}$ and revealed a signet ring cell carcinoma, with the deepest invasion

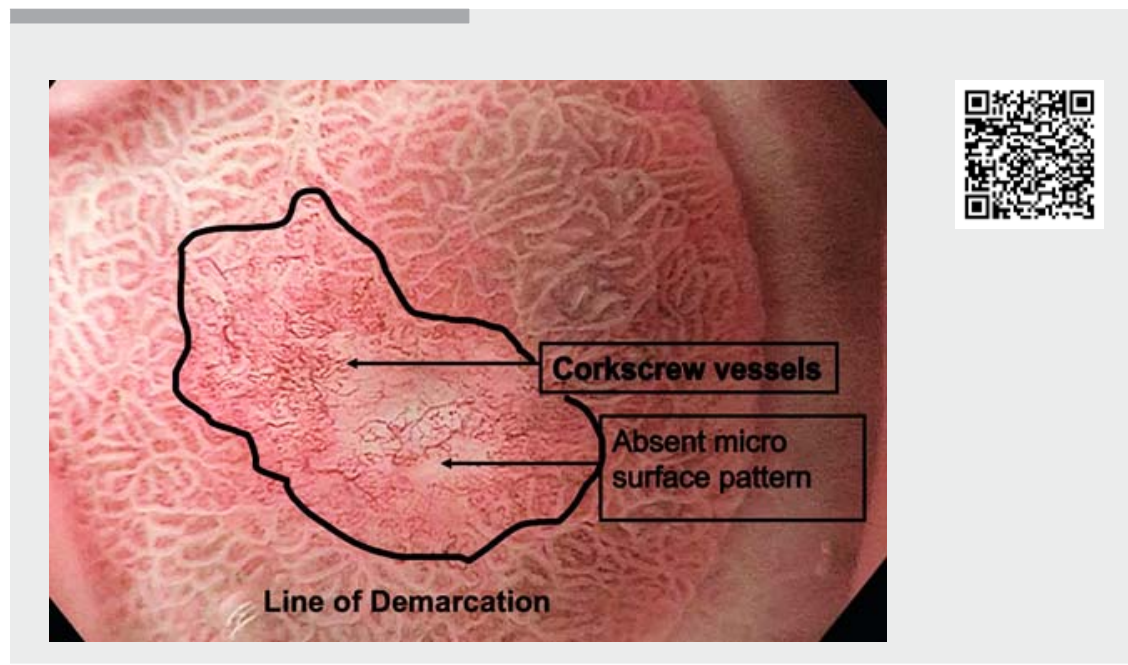

Video 1 Endoscopic curative resection of undifferentiated early gastric cancer.
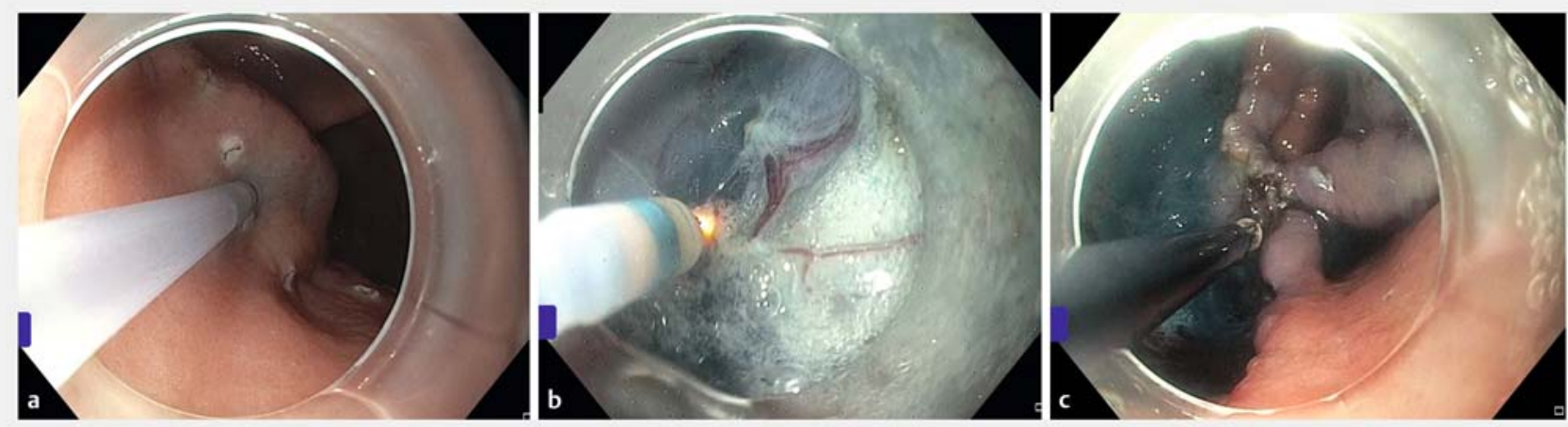

Fig. 2 Resection of the lesion. a Submucosal lift using indigo carmine mixed with (0.9\%) normal saline solution. b Submucosal dissection using the Dualknife 'J' (Olympus Corp. Tokyo, Japan). c Dissection was completed using the ITknife2 (Olympus Corp.). 

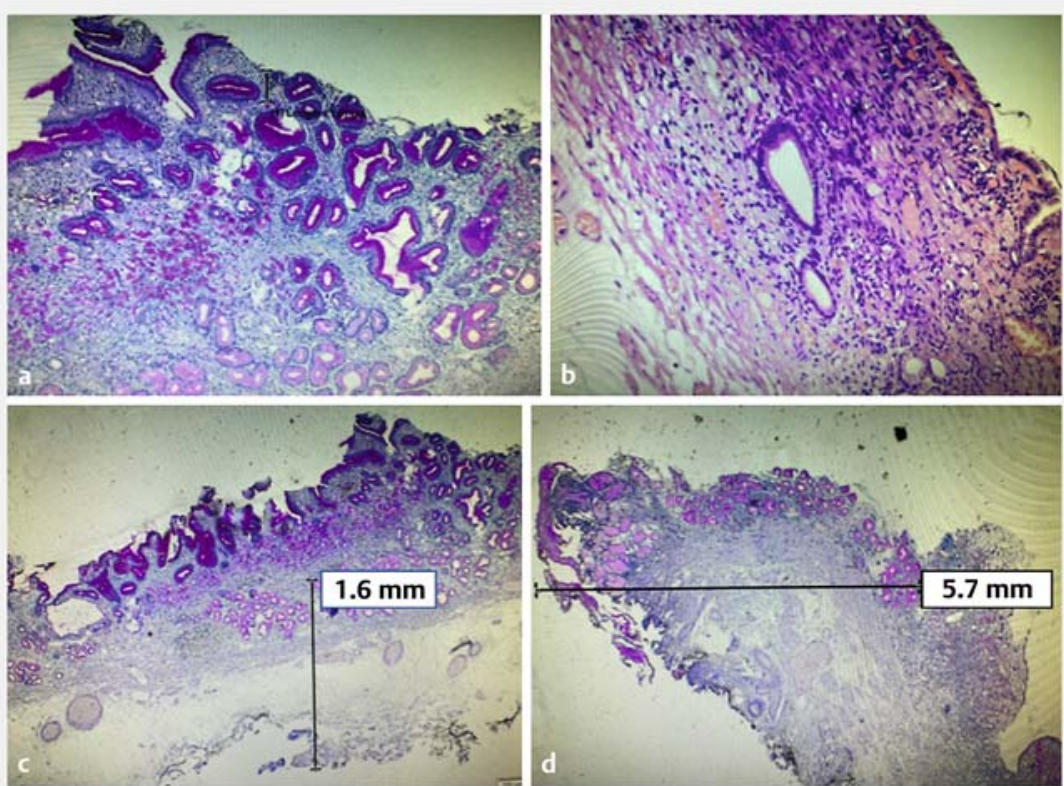

- Fig. 3 Histological analysis. a Periodic acid-Schiff-Alcian blue staining showed a poorly differentiated adenocarcinoma, with muscularis mucosae free from tumor invasion. b Signet ring cells infiltrated the lamina propria. $\mathbf{c}, \mathbf{d}$ Specimen showed tumor-free vertical and horizontal margins (respectively 1.6 and $5.7 \mathrm{~mm}$; Type 0 Ilc, pT1a ULO, Ly0 V0, pHM0, pVMO).

confined to the mucosa and negative margins ( $\triangleright$ Fig.3). Follow-up esophagogastroduodenoscopy after 1 year showed resolution of the lesion with no recurrence.

Magnification endoscopy with $\mathrm{NBI}$ is a useful modality that helps to characterize and manage early gastric carcinoma, and in our case prevented gastrectomy.

Endoscopy_UCTN_Code_CCL_1AB_2AD_3AB

\section{Competing interests}

The authors declare that they have no conflict of interest.

\section{The authors}

Aniruddha Pratap Singh', Pradev Inavolu', Anuradha Sekaran ${ }^{2}$, D. Nageshwar Reddy ${ }^{1}$, Mohan Ramchandani ${ }^{1}$

1 Department of Medical Gastroenterology, Asian Institute of Gastroenterology, Hyderabad, Telangana, India

2 Department of Pathology, Asian Institute of Gastroenterology, Hyderabad, Telangana, India

\section{Corresponding author}

\author{
Mohan Ramchandani, MD \\ Department of Medical Gastroenterology, \\ Asian Institute of Gastroenterology, \\ Mindspace Road, Gachibowli, Hyderabad, \\ Telangana 500032, India \\ Fax: +91-40-42444222 \\ ramchandanimohan@gmail.com
}

\section{References}

[1] Yokoyama A, Inoue H, Minami $\mathrm{H}$ et al. Novel narrow-band imaging magnifying endoscopic classification for early gastric cancer. Dig Liver Dis 2010; 42: 704-708

[2] Yu H, Yang AM, Lu XH et al. Magnifying narrow-band imaging endoscopy is superior in diagnosis of early gastric cancer. World J Gastroenterol 2015; 21: 9156

[3] Kaise M. Advanced endoscopic imaging for early gastric cancer. Best Pract Res Clin Gastroenterol 2015; 29: 575-587

[4] Muto M, Yao K, Kaise M et al. Magnifying endoscopy simple diagnostic algorithm for early gastric cancer (MESDA-G). Dig Endosc 2016; 28: 379-393

[5] Nakayoshi T, Tajiri H, Matsuda K et al. Magnifying endoscopy combined with narrow band imaging system for early gastric cancer: correlation of vascular pattern with histopathology (including video). Endoscopy 2004; 36: 1080-1084

\section{Bibliography}

Endoscopy 2021; 53: E226-E227

DOI 10.1055/a-1244-9690

ISSN 0013-726X

published online 11.9.2020

(C) 2020. Thieme. All rights reserved.

Georg Thieme Verlag KG, Rüdigerstraße 14, 70469 Stuttgart, Germany

\section{ENDOSCOPY E-VIDEOS}

https://eref.thieme.de/e-videos

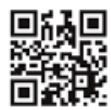

Endoscopy E-Videos is a free access online section, reporting on interesting cases and new techniques in gastroenterological endoscopy. All papers include a high quality video and all contributions are freely accessible online.

This section has its own submission website at https://mc.manuscriptcentral.com/e-videos 